\title{
Posthumous Harm, Punishment and Redemption
}

\begin{abstract}
The idea that we can harm the living is uncontroversial. By comparison, the idea that we can harm the dead is highly controversial. Chapter 3 explores the intelligibility and plausibility of ante-mortem harm, posthumous harm and redemption. This chapter addresses the following questions: Is it possible or impossible to harm the dead? What is ante-mortem harm? How is ante-mortem harm intelligible and how is it not? How might we reframe the harm of death? How might we characterise harms to the dying? What is posthumous harm and how is it intelligible? What is the relationship between dismembering the corpse and disremembering persons? How can we distinguish different kinds of posthumous harm (posthumous harm from posthumous punishment for example)? How might we understand posthumous redemption as a counterpoint to harm?
\end{abstract}

Keywords Intrinsic - Posthumous harm and punishment - Symbolic and narrative harm

\section{The Impossibility of Posthumous Harm}

It is often taken for granted that we can harm the living, but not the dead. A classical view on the impossibility of posthumous harm comes out of the empirical philosophy of Epicurus.

F. Tomasini, Remembering and Disremembering the Dead, Palgrave Historical Studies in the Criminal Corpse and its Afterlife, DOI 10.1057/978-1-137-53828-4_3 
Epicurus offers us a consolation of philosophy, one that attempts to relieve us of the fear of death. Epicurus's therapeutic philosophy corrects what he sees as philosophical errors that generate an anxiety about an afterlife, or a fear of the event of death itself.

Epicurus was a materialist, subscribing to the atomic theory of the presocratic philosopher, Democritus. According to Epicurus 'the human soul is composed of eternal particles which experience sensation only while united with the body' (http://newepicurean.com, sect. 6). He argued that everything, in an infinite amount of combinations, was composed of atoms, including the soul, which he believed to be material. Epicurus relied on empirical evidence of his senses to make judgements and evaluations about the world around him and, through this, reasoned that the soul was the animating materiality that gave locomotion to the body and expression to the features. He believed there was little sense in claiming that the soul was immaterial or incorporeal because 'something that was void could neither act or be acted upon and the soul acts and is acted upon' (http://newepicurean.com, sect. 6). He therefore rejected the view that an immaterial or incorporeal soul existed. This being the case, any anxiety about an afterlife, spurred on by theistic faith, was unnecessary.

Having rejected the immortality thesis (the afterlife of the soul), Epicurus insists that death itself is not something to fear, but an event that we should be indifferent to. In his words:

Become accustomed to the belief that death is nothing to us. For all good and evil consist in sensation, but death is the deprivation of sensation... So death, the most terrifying of ills, is nothing to us, so long as we exist, death is not with us; but when death comes, then we do not exist. It does not then concern either the living or the dead, since the former it is not, and the latter are no more. (Epicurus 1940, p. 31)

As many writers have noted there are two distinct strands of argument entangled within this succinct position. The first strand relies on what may be called the experience requirement: that is, 'good and evil consists in sensation'. Whereas the second strand is founded on what philosophers have called the existence condition: that is, 'death is nothing to us when we do not exist'.

While it is possible to critically separate the two strands of argument, it is more difficult to reject the argument as a whole. This is because the weaker first strand is inextricably woven and linked with Epicurus' stronger second. So while it is worth picking apart some of the weaker 
claims Epicurus makes, the Epicurean argument taken as a whole is stubbornly resilient.

The first strand of argument draws on the presupposition that all that matters about death is experience. This is encapsulated in what may be called the experience requirement that is expressed in the second sentence.

The idea that 'all good and evil consists in experienced sensation' is vulnerable to criticism. Nagel, for example, rejects this:

Most good and ill fortune has as its subject a person identified by his history and his possibilities, rather than merely by his categorical state of the moment - and while the subject can be exactly located in sequence of places and times, the same is not necessarily true of the goods and ills that befall him. (Nagel 1970, p .77)

To illustrate the above, Nagel imagines an intelligent adult who suffers a brain injury. The person who has suffered the brain injury is well cared for and now has the mental condition of a contented infant. Nagel argues that this person has undergone a grave misfortune; not because the person is now on the level of a contented infant, but because the intelligent adult has lost their intelligence. In other words, there are goods or interests that may lie beyond awareness and the immediate experience of being harmed (Nagel, cited in Belliotti 2013, pp. 25-26).

Epicurus also claims that 'death as the deprivation of sensation is neither good nor bad for us' but something that we should treat indifferently.

This prompts an obvious objection: 'once we are dead, while we can no longer suffer painful experiences, we can no longer experience pleasurable ones either' (Scarre 2007, p. 87). For this reason alone, it is very difficult to treat death indifferently. For those of us who find a positive value in being alive 'any reason to (want to) live is an excellent reason to want not to die...' (Luper-Foy 2002, cited in Scarre 2007, p. 103). Moreover, the converse is also true: there might be good reasons to be dead if life turns out badly. Either way, from the perspective of being thrown into a life that has to be lived in one way or other, it is difficult for death to be nothing to us.

Epicurus goes on to claim '...death, the most terrifying of ills, is nothing to us, so long as we exist death is not with us...'. Epicurus here is presumably running with a binary notion of death: death as an absolute state versus being uncomplicatedly alive. While it is true to say we are not harmed by the absolute state of being dead, it is 
not true to say that death is not with the living when they are in fact dying. To unpack this further: while it may be logical to be indifferent to the state of being dead when there is no subject to experience anything at all, it is equally logical to fear death as a process; to grieve partial loss of our faculties and express its often painful passage.

In sum, Epicurus does not consider the death in dying which can be painful and distressing since it is already busy taking away that which we value most about living. However, while Epicurus either remains silent or unaware of this complication, it is a digression from the spirit of what Epicurus is fundamentally asking us to imagine.

To rephrase from the perspective of being uncomplicatedly alive, perhaps wholly healthy, we can afford to be indifferent about death because we are securely outside of its grip on us. More persuasively still, Epicurus is inviting us to embrace the possibility of the total annihilation of being dead; that is, 'death is nothing to us,' precisely because there is no subject that experiences good or bad.

The annihilation of the subject by biological death seems Epicurus's most unassailable strand of argument. It rests on what Fred Feldman (1991) first called the 'Existence Condition' and the proposition that 'nothing either good nor bad can happen to a subject $s$ at time $t$ unless $s$ exists at $t^{\prime}$ (cited in Scarre 2007, p. 89). To be harmed a person has to first $b e$. So, if there is no subject to suffer the harm of death, there can be no harm.

Looking at the problem in the round, there are three major strategies in dealing with the existence condition where absolute death cannot harm us:

- Agree with Epicurus, by following his assumption that the state of being dead can mean nothing to us because we cease to exist as subjects that can be harmed (Partridge 1981);

- Circumvent the existence condition by posing an alternative: ante-mortem harm. This allows us to contemplate 'the misfortunes of the dead' (Pitcher 1984) by seeing how posthumous events throw a light on blocked interests of persons that once existed (Feinberg 1984). The Feinberg-Pitcher position has inspired a wealth of conceptual criticisms and some interesting variations on the ante-mortem harm thesis from a wide variety of 
contemporary philosophers (Belliotti 2013). This is beyond the scope of this chapter;

- Meet the existence condition head on by reframing posthumous harm and the annihilation thesis. This involves understanding how subjectivity might survive death, and how it might be employed to make posthumous harm an intelligible concept (Scarre 2007; Sperling 2008; Belliotti 2013; Tomasini 2009).

\section{Death and Ante-Mortem Harm}

The idea that we cannot harm the dead has a long historical root in classical philosophy. Yet it is an idea that has fascinated and vexed contemporary philosophers.

Some philosophers like Ernest Partridge agree with Epicurus, elaborating why the dead are beyond harm:

Nothing happens to the dead... Accordingly, after death, with the removal of a subject of harms and bearer of interests, it would seem that there can be neither 'harm to' nor 'interests of' the descendent. (Partridge 1981, p. 253)

Pitcher was one of the first philosophers to realise that while Epicurus's argument might be difficult to wholly dismiss, it can be successfully circumvented by posing a different kind of subject to which harms might accrue.

Pitcher accepts the annihilation thesis and asks: 'the dead, if they exist at all, are so much dust. How is it possible for so much dust to be wronged?'(Pitcher 1984, p. 183). In answering his own question he distinguishes between two kinds of subject. The post-mortem subject, call him Harry, perhaps mouldering away in some grave, and the ante-mortem Harry, as he was at some stage of his life before he died. According to Pitcher, while death cannot be bad for Harry's corpse it can be bad for the ante-mortem Harry.

Feinberg agrees with the Pitcher thesis and elaborates on the idea of ante-mortem harm. What follows is philosophical convergence, which brings together Feinberg and Pitcher, and that might for the sake of convenience be referred to as the Feinberg-Pitcher account.

According to Feinberg-Pitcher it is not intelligible to talk of a subject's survival after physical death, nor does it make sense to talk of 
harming posthumous interests without a surviving interest-bearer. As such they rule out the possibility of posthumous harm.

So how are ante-mortem persons harmed by death? The answer lies in the fact that ante-mortem persons have transcendent interests; interests that can only be fulfilled or thwarted after they are dead. The FeinbergPitcher account argues that transcendent interests may be frustrated by death. So: 'the subject of harm in death is the living person ante-mortem, whose interests are squelched' (Feinberg 1984, p. 93).

This conclusion about who is harmed has important consequences for the timing and causation of harm. In Feinberg's own words:

The ante-mortem person was harmed in being the subject of interests that were going to be defeated whether he knew it or not... It does not become retroactively true that as a subject of doomed interests he is in a harmed state: rather it was true all along... Exactly when did the harmed state of the ante-mortem person, for which the posthumous event is 'responsible', begin...' at the point, well before his death, 'when the person had invested so much in some post-dated outcome that it became one of his interests. (Feinberg 1984, pp. 89-90)

Ante-mortem harm purposely avoids the problem of the objectionable backwards causation (what happens in the future can causally affect what happened in the past). Instead Feinberg is proposing that a person who is harmed ante-mortem was going to be harmed 'all along' by an awaiting event. In a reiteration of Feinberg's words, 'the ante-mortem person was harmed in being the subject of interests that were going to be defeated whether he knew it or not'.

Let us look at a brief biography of Private James Highgate (Watson 2014) who was shot at dawn during the First World War and posthumously dishonoured, to illustrate the point. What follows is a brief timeline of significant events:

- 13 May 1895: Thomas James Highgate is born

- 4 Feb. 1913: Highgate enlists at the age of 17 (and officially commits to a youthful interest in living a life as an honourable soldier)

- 28 July 1914: World War One begins

- 8 Sept. 1914: Highgate is shot at dawn for desertion

- 1920: Private Highgate's name was left off his local war memorial in the village of Shoreham, Kent. Unlike his comrades, his name was omitted. 
- 2006: Private Highgate is posthumously pardoned by Labour Government along with 305 other soldiers dishonoured by being 'shot at dawn' for various offences un-becoming of a fighting soldier

- 2014: Private Highgate's name is still missing from the Shoreham war memorial, despite the blanket pardon in 2006.

According to the Feinberg-Pitcher account, when the erection of a war memorial occurred in the village of Shoreham in 1920, the deliberate omission of private Highgate's name could not harm him, as harm is something that only accrues to living persons.

The omission of Thomas Highgate's name from his local war memorial does harm the ante-mortem Highgate's interest in having an unambiguous career as an honourable soldier. This posthumous event (the omission) throws into stark relief that ante-mortem Highgate had been 'playing a losing game' (Feinberg 1984, pp. 91-92) from the moment he developed the interest of being an honourable soldier to the time his name is still missing from the war memorial in 2014.

The Feinberg-Pitcher account is seductive and clever. It skilfully avoids metaphysical pitfalls such as backwards causation, whilst also helping to explain our moral intuitions about how Highgate may have been wronged.

In doing so, the Feinberg-Pitcher thesis might explain how death itself harms ante-mortem interests, without begging the question, how can harm affect non-existent persons? In sum, the Feinberg-Pitcher antemortem harm thesis seems to solve the tricky existence condition.

However, some telling criticisms remain.

The first criticism stems from the intuition that a significant harm seems to flow from a post-mortem event of his name being omitted from a war memorial in Shoreham village. However, the Feinberg-Pitcher thesis circumvents this intuition because they are still running with the Epicurean annihilation thesis: it is only possible to harm living subjects, not the deceased. Instead of concluding, like an Epicurean might, with a straightforward 'no harm' conclusion, faithful followers of the FeinbergPitcher thesis would be forced to argue that ante-mortem Highgate interests were harmed.

By denying the problem of backwards causation, the Feinberg-Pitcher account is vulnerable to yet another causation problem: phantom causation. In the historical example, the fact that Highgate's name was left 
off the Shoreham war memorial is not a cause of harm to Highgate, according to the Feinberg-Pitcher thesis. Feinberg-Pitcher do not take into consideration posthumous harm to someone's reputation, they only consider ante-mortem harm. This is a definite weakness in their account, since it is counter-intuitive not to recognise that there was harm done to Highgate's memory and reputation by ommitting his name from the local war memorial.

The Feinberg-Pitcher thesis has no causal force when it comes to explaining posthumous harms to Highgate. To follow such an ante-mortem thesis requires an appeal to obfuscating language that problematises cause. In other words, the author would need to borrow Feinberg's puzzling language; that is, it is clear that Highgate's interests were harmed 'all along' and that by being left off the war memorial Highgate was 'playing a losing game' in his transcendent interest for honour.

Setting aside the obvious importance of the mortem harms-his trial and execution-it is deeply counter-intuitive to think that leaving Highgate's name off the official war memorial in 1920 was not further harming Highgate in some way.

According to Feinberg-Pitcher we can only squelch transcendent interests of ante-mortem persons. This is unnecessarily restrictive, as it is possible to think of harms in relation to social death as well harms in relation to biological death. In the case of the latter, narrative or ipse identity survives in the form of memory and biography that is refigured by others who survive the deceased. So leaving Highgate's name off the Shoreham war memorial was a symbolic harm to Highgate's memory.

In the author's view it is possible to avoid the problem of phantom causation by broadening out what can be harmed when.

In sum we need to distinguish between the configuration of antemortem interests that can be thwarted (Feinberg and Pitcher) and refiguration of a deceased person's memory by others, which, in turn, is also subject to a harm experience by those that survive the dead.

There are two responses to the Feinberg-Pitcher account.

The first is to view it as wrong because it fails to satisfactorily deal with some important timing and causation problems. In my opinion this is uncharitable and mistaken. The Feinberg-Pitcher ante-mortem thesis makes huge strides into conceptualising the harm of death.

The second is to view the argument as an unnecessarily restrictive account of harm, one that does not consider other possibilities. The serious criticism, in the author's view, is that the Feinberg-Pitcher thesis is 
running with an overly narrow account of annihilation, one that fails to fully consider how personal identity may survive death. This leads to an over-simplistic assignation of categories, dichotomising harm between the possibility of ante-mortem harm on the one hand, and impossibility of posthumous harm on the other.

\section{The Harm of Death Reframed}

There seems to be a narrow choice on offer: either agree with Epicurus et al. on the annihilation thesis and the impossibility of the posthumous harm, or circumvent the problem by posing ante-mortem harm (Feinberg-Pitcher). To move beyond this dichotomy we need to think about the problem more broadly and reframe the terms upon which some assumptions about harm and death rest.

\section{The Meaningfulness of Life Beyond Death}

The notion that death should be 'nothing to us', as Epicurus puts it, is difficult to reconcile with desires that give meaning to our lives beyond our sense of self-satisfaction. That the meaningfulness of life extends beyond death is testified by our transcendent interests or desires. Or, as Belliotti puts it: 'my biographical life transcends my biological life' (Belliotti 2013, p. 102).

Transcendent desires surpass the timing of our own death and, in a search for meaningfulness outside ourselves, we go beyond the self-satisfaction of meeting our needs and personal preferences in the present moment. Transcendent interests or desires include: the honouring of death bed promises; the disposal of our property and belongings after death; the integrity of our posthumous reputation; the respectful disposal of our corpse according to religious belief and custom; the flourishing of children, relatives and friends; and the successful completion after death of creative endeavours or projects begun in life.

These desires resonate with the human aspiration 'to mould objectively worthy lives' (Belliotti 2013, p. 103). As such they do not flow from internal satisfaction alone. The hedonistic thesis would have it that life is the sum of all worthwhile individual preferences satisfied. However we also need our life to mean something beyond itself. Indeed, transcendent desires flow from a sense that a meaningful life has an 
'external vantage point' (Belliotti 2013, p. 103), one that contributes to a wider and deeper personal, human and cosmic perspective.

From a personal point of view we care about those we leave behind when we die-children, family and friends. We want to be remembered faithfully, for what our life stood for. Moreover, it is natural that we might bequeath finances, property and belongings to ensure the welfare of significant others. Less tangibly, we believe that our search for meaning is often carried over by our children and their children. In terms of our death, we care that our corpse is respectfully treated-remembered both literally and figuratively after life.

From a wider connection to humanity our life might mean something in respect to creative works we leave behind: uncompleted projects for the wider good of society, fictional, non-fictional works and/or practical projects like scientific endeavours that promote a sense of progress.

Finally, from a cosmic point of view, we may believe that our life means something beyond our material embodied existence. This has ramifications for how we treat the human body when dead. Many people throughout history have been socially conditioned in complex ways by religious and folkloric fears born out of a belief not to 'harm' the dead, lest it hinders safe-passage of the soul in the afterlife.

For those of us who have forgone religious superstition about a disembodied afterlife, it might be important for our lives to have counted for something greater than the sum of its remembered parts. For example: a view that a life lived expresses a solidarity with others, or unity with a natural ecological order of things, all of which might be sensitively reflected in a burial ritual.

\section{Reconsidering the Annibilation Thesis and Existence Condition}

One way of assessing the possibility of posthumous harm is to reframe what it is meant by annihilation and existence.

The original formulation of the annihilation thesis is Epicurean: beings cannot be harmed posthumously because at death subjects are annihilated and are thus beyond all experience.

For the sake of this particular argument let us assume, alongside Epicurus, that a life after death is false (although it would be wiser to be agnostic about it). Then Epicurus's assertion that death puts us beyond all experience is likely to be true, as it is impossible to imagine experience without existing in some sense or other. 
Epicurus also asserts that all good and evil consist of experience. This assertion, by itself, is difficult to support and much easier to challenge. Epicurus here is running with a highly questionable hedonistic assumption: pleasure and pain define what is good or bad for us. This is true if we understand harm in a very narrow sense of pain or hurt. However, harm may be distinguished from hurt (Belliotti 2013, p. 11). While hurt involves suffering to which we accrue a negative valence through the commonplace expression 'it hurts', harm is something that can happen without necessarily being consciously aware that it is happening.

The classic example that may be used to illustrate this is the case of a peeping Tom spying on our private life. While the peeping Tom may, undiscovered, never hurt us, his actions nevertheless harm a desire for privacy (Belliotti 2013, p. 11). Likewise, while harming a dead body cannot physically hurt the deceased, it can harm the ante-mortem person who holds certain beliefs about how their corpse ought to be treated post-mortem. Whether these beliefs are credible or not is much less important than the fact that they can be harmed by not being respected.

One of the reasons why harms are so much more far reaching than hurts is that they are not constrained by the immediacy of subjective experience and preference satisfaction. As already argued, for a life to be meaningful it often needs to be considered to have a meaning from an external vantage point beyond itself. Harms to the dead outstrip the experiential constraint of hurt for this reason. While it might be absurd to think that we might hurt the dead, it is possible to harm the interests of persons that once existed. It is this posthumous harm, involved in intentionally disremembering someone after they have died, that the Feinberg-Pitcher thesis cannot easily account for.

The Feinberg-Pitcher thesis is right to acknowledge the Epicurean limitation to the annihilation thesis by arguing that the end of the experiencing subject does not spell the end of discussion about the misfortunes of the dead. This is certainly an advance on Epicurus and his modern exponents, like Partridge, who do not seem to puzzle through the possibility of harming the interests held by persons that once existed.

Equally the Feinberg-Pitcher thesis is wrong to draw the distinction too tightly between the possibility of ante-mortem harm and impossibility of posthumous harm. 


\section{Towards a Typology of Harms}

For reasons of analytical clarity it is worth distinguishing between different orders of harm.

- First order intrinsic harms, which causally affect living persons and not dead bodies. The dead body, by virtue of being a corpse is beyond experiencing intrinsic harm of any order.

- First and Second order symbolic harms are either harms to the interests of those who once existed (first order symbolic harms to antemortem persons), or they are biographical harms that occur after death and to a posthumous reputation (second order symbolic harms). The Feinberg-Pitcher thesis considers the first, but not the second. First order symbolic harms accrue to the transcendent interests of ante-mortem persons.

Second order symbolic harms are harrmful post-mortem re-figurations of what once living persons interests were thought to be. They can be thought of as harms to memory and biography. Posthumous harms, moreover, are not free-floating, they accrue to a living subject bearer, normally in the form of a relative or friend who is concerned that the memory of their dead is not misrepresented. The living are witness to the fidelity of memory and its rightful conservation. They are surrogate interest bearers for the transcendant interests of those now dead.

- Second order intrinsic harms are intrinsic harms to significant others who are related to or care about the deceased and experience the hurt of how they are disremembered. They tend to be psychological harms and rely in a narrative investment about how someone ought to be remembered. Being disremembered causes psychological distress in those that invest truth in a certain memorial narrative. Most commonly, it may be experienced by survivors who hear others 'speaking ill' of their dead relatives or friends. More dramatically it may be experienced by a relative as a deliberate and intentional attempt to dishonour the dead and even to refigure their memory as particularly notorious. Usually disremembering the dead is expressed through the spoken or written word when this is not what they deserved.

Second order intrinsic harms can be experienced by others as harm to the corpse itself. While it is not possible to harm a mouldering corpse in itself, the corpse has a symbolic unity for the living that needs to be respected, in particular by those who grieve 'their' 
dead and experience inappropriate dismemberment as harm to memory and religious belief.

\section{Reviewing and Previewing Harm and Redemption of Dying AND BEING DEAD}

What follows is a brief review and preview of some of the responses to some of the standard conceptual assumptions around death and dying, whereby posthumous harm is thought to be unintelligible and nonsensical.

\section{First Assumption: We Are Either Dead or Alive}

This view does not take into account death that occurs in the process of dying.

Both the Florida Boy and Tony Bland case in Chap. 1 showed that it is possible to remain technically alive (in a biological sense), but still have undergone a significant social, autobiographical death. Symbolic or narrative death therefore, can occur before biological death has unambigiously ended.

\section{Second Assumption: Ante-Mortem Harm Is Possible, Posthumous Harm Is Not}

There is an assumption that in order to circumvent the existence condition, it is possible to talk about ante-mortem harm but not possible to talk about posthumous harm because at this point the subject bearer of harm no longer exists. Again, this is true, but nevertheless flows from an overly narrow view of what it means to exist. For example, it is perfectly intelligible to talk of a person's narrative still existing long after they are dead through memory and biography. Harms to the memory and biography of the dead are second order symbolic harms.

\section{Third Assumption: It Is Possible to Harm a Living Person but Not Their Corpse}

This view maybe attributed to many philosophers post-Epicurus who run with the idea that harm necessarily invokes the idea of intrinsic harm. 
It is by invoking a notion of biological death that we can understand intrinsic harm; only living persons undergo real changes that are subject to intrinsic harms. From this perspective, it is nonsensical to talk about harming an ex-person's ashes or their mouldering corpse.

While this is all true, it does not take into account the idea of social death-where relational changes happen as a consequence of real or intrinsic changes involved in biological death. In other words, while it may not be possible to intrinsically harm the dead body, it is possible to symbolically harm the memory and biography of the dead persons that once existed through inappropriate dismemberment. In Chap. 5 the symbolic harm to memory is explored through complicated grief. Relatives who had been subject to the shock of hearing that their dead children had been dismembered through inappropriate post-mortem procedures at Alder Hey in the 1990's, had difficulty remembering their children as they were in life. This involves both second order symbolic and intrinsic harm. Symbolic because it involves descration of the corpse and what this represents and intrinsic because it is psychologically distressing to experience this.

On another level, dismembering the dead is an assault on cultural and spiritual beliefs about how the dead should be treated after life. For example, in the eighteenth century, criminals who had been sentenced to posthumous punishment after hanging, by having their body's dissected or gibbetted, feared that dismemberment would stymie their soul attaining peace, rest or resurrection in the afterlife.

From a conceptual point of view, the prospect of harming the body after death is a second order symbolic harm to certain spiritual and religious beliefs about a life hereafter (see Chap. 4 and Chap. 5). Furthermore because it is an anticipated symbolic harm that involves imagining what might happen to them in a life hereafter, it also causes psychological suffering.

Posthumous harm becomes posthumous punishment when it deliberately involves state power. Posthumous punishment is a form of retributive justice and involves a further punishment through dismemberment in addition to capital punishment. It is an act of what Bourdieu calls symbolic power/violence (Bourdieu 1992, 1996 cited in Crossley, 2005) where dismemberment through gibbetting or dissection literally involves state authority inscribing a 'mark of infamy' on the criminal corpse. 
Symbolic violence also involves a second order intrinsic harm, because the act disremembering the dead causes psychological distress in those that are confronted with that refiguration of memory. The idea of overt intentional symbolic harm to the dead in Chap. 4 constitutes posthumous punishment by the state and needs to be distinguished from posthumous harm, that involves a form of instutional collusion to perpetrate symbolic harm (see Chap. 5).

\section{Fourth Assumption: Posthumous Redemption/Pardoning Is Impossible and Pointless}

The corollary of posthumously punishing those shot at dawn was their subsequent posthumous pardoning. This is explored at length in Chap. 4, where the author critically examines the case for and against posthumously pardoning those shot at dawn during the First World War.

Posthumous punishment by being dishourably shot at dawn by one's own men in the First World War was a symbolic harm to soldier's reputation after they are dead. Because capital punishment and its narrative aftermath is a reinterpretation of the narrative events that judges a soldier to be 'deserter' or 'coward' worthy of being shot, it is a secondary symbolic harm. Moreover, those dishonourably executed at dawn in this way, had very real psychological consquences on the men awaiting execution and those relatives that have had to live with this family dishonour.

Posthumous pardoning is an act of symbolic redemption (second order because it is refiguring a narrative of a life lived that has been damaged).

A posthumous pardon is not about rewriting the past as some have argued (Corns and Hughes-Wilson 2002), but a re-evaluation of historic judgments from a new perspective, one that sits alongside a historic judgment. This matters on many levels, not least because it rehabilitates the fidelity of a narrative identity once disremembered. It also acts as a form of forgiveness by taking away the stigma from relatives who have had to live with the dishonour of their ancestor's fate.

\section{Summary}

This third chapter builds on the conceptual foundations of the second, conceptualising posthumous harm, punishment and redemption. The major obstacle in theorising the possibility of harm after death is the existence condition. We need to have existed in order to be the subject 
of harm. It is possible to understand harm in five ways: we can intrinsically harm existing persons; we can harm the transcendent interests of persons that once existed; we can symbolically harm the narrative identity of persons facing their death; we can symbolically harm the memory and biography of the dead; and we intrinsically harm how the dead continue to be remembered through the experience of significant others who feel their dead have been unjustly and harmfully remembered.

If it is possible to conceptualise the possibility of posthumous harm, it is necessary to distinguish posthumous harm from posthumous punishment, where the latter involves a deliberate use of state or symbolic power in order to disremember posthumous identity. Finally, if it is possible to posthumously harm persons through their biography, it is also possible to posthumously redeem their narrative identity through a posthumous pardon.

Discussions in the chapters that follow are marked by a shift in emphasis of concern. Instead of fore-grounding conceptual matters, Chaps. 4 and 5 fore-ground the importance of historical and empirical case studies, occasionally using conceptual insight to further illuminate case study analysis.

\section{REFERENCES}

Belliotti, R. (2013). Posthumous harm: Why the dead are still vulnerable. New York: Lexington Books.

Bourdieu, P. (1992). Language and symbolic power. Cambridge: Polity.

Bourdieu, P., \& Passeron, J. (1996). Reproduction. London: Sage.

Corns, C., \& Hughes-Wilson, J. (2002). Blindfold and alone: British military executions in the great war. London: Cassell.

Crossley, N. (2005). Key concepts in critical social theory. London: Sage.

Epicurus. (1940). Letter to Menoeceus. In The stoic and Epicurean philosophers. W. J. Oates (Ed.) \& Bailey, C. (Trans.). New York: The Modern Library.

Feinberg, J. (1984). Harm to others. New York: Oxford University Press.

Feldman, F. (1991). Some puzzles about the evil of death. Philosophical Review, 100, 205-227.

Luper-Foy, S. (2002). Death. Stanford Encyclopaedia of philosophy. Retrieved January 19, 2006, from http://plato.stanford.edu/enteries/death.

Nagel, T. (1970). Death. Nous, 4, 73-80.

NewEpicurean.com-Elemental Edition, Letter to Herodutus. Retrieved January 19, 2016, from http://newepicurean.com/epicurus/letter-to-herodotus-elemental-edition/. 
Partridge, E. (1981). Posthumous interests and posthumous respect. Ethics, 91, 243-264.

Pitcher, G. (1984). The misfortunes of the dead. American Philosophical Quarterly, 21, 183-188.

Scarre, G. (2007). Death. Stocksfield: Acumen.

Sperling, D. (2008). Posthumous interests. Cambridge: Cambridge University Press. The Murder Act (1751) (25 Geo 2 c 37).

Tomasini, F. (2009). Is posthumous harm possible? Understanding death, harm and grief. Bioethics, 23(8), 441-449.

Watson, G. for BBC News. Retrieved January 19, 2016, from http://www.bbc. co.uk/news/uk-england-25841494.

Open Access This chapter is licensed under the terms of the Creative Commons Attribution 4.0 International License (http://creativecommons. org/licenses/by/4.0/), which permits use, sharing, adaptation, distribution and reproduction in any medium or format, as long as you give appropriate credit to the original author(s) and the source, provide a link to the Creative Commons license and indicate if changes were made.

The images or other third party material in this chapter are included in the chapter's Creative Commons license, unless indicated otherwise in a credit line to the material. If material is not included in the chapter's Creative Commons license and your intended use is not permitted by statutory regulation or exceeds the permitted use, you will need to obtain permission directly from the copyright holder.

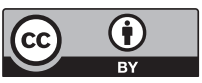

